\title{
Considerações sobre o modelo de seleção pelas consequências: o que mudou em 28 anos? ${ }^{1}$
}

\author{
Maria Helena Leite Hunziker \\ Universidade de São Paulo
}

\begin{abstract}
RESUMO
Este artigo compara dois conjuntos de textos publicados no Brasil, em 1988 e 2016, focados na análise do modelo de seleção pelas consequências proposto por Skinner. São apresentados os contextos acadêmicos em que os dois conjuntos foram produzidos, um breve resumo das principais contribuições de cada texto, fazendo uma comparação entre eles para vislumbrar a evolução que se deu na comunidade de analistas de comportamento no Brasil ao longo dos últimos 28 anos. No final, sugere-se que novas publicações possam analisar dados experimentais recentes e sua compatibilidade com o nível ontogenético de seleção por consequências, complementando as considerações teórico-filosóficas aqui apresentadas em relação à seleção nos níveis filogenético e cultural.
\end{abstract}

Palavras-chave: Seleção pelas consequências; experimentação; Skinner.

\begin{abstract}
Considerations about the selection by consequences model: what has changed in 28 years?

This article compares two sets of texts published in Brazil, in 1988 and 2016, focused on the analysis of the selection by consequences model proposed by Skinner. It is presented the academic contexts in which the two sets were produced, a brief summary of the main contributions of each text, making a comparison between them in order to glimpse the evolution that has taken place in the community of behavior analysts in Brazil along of the last 28 years. In the end, it is suggested that new publications could analyse recent experimental data regarding their compatibility with the selection on the ontogenety level, complementing the theoretical/philosophical considerations presented here about the selection on filohenetic and cultural levels.
\end{abstract}

Keywords: Selection by consequences; experimentation; Skinner.

\author{
Tomemos a evidência por juiz único da verdade e, se a \\ evidência nos faltar, saibamos duvidar. \\ (Giordano Bruno, séc. XVI) \\ Nenhuma prática é imutável. Mude e esteja pronto a \\ mudar novamente. Não aceite verdade eterna. \\ Experimente. \\ (B.F. Skinner, séc. XX)
}

Cientistas são fruto de sua época, sendo o "fazer ciência" moldado pelas contingências individuais e culturais do grupo social. Assim, é ilusório pensar que determinadas propostas teórico/científicas são, em si, boas ou más, aceitáveis ou reprováveis, independente da época. Propostas que já contribuíram para o avanço da ciência em outros tempos hoje podem não ter qualquer relevância, tendo sido substituídas por outras mais adaptadas às informações disponíveis nos tempos atuais. Um exemplo emblemático é a visão que se tinha da posição central da Terra, em torno da qual giravam os demais astros, incluindo o Sol. Novas informações trazidas por pesquisadores, como Giordano Bruno e Galileu, produziram mudanças radicais na compreensão da astronomia, não sem antes provocarem forte resistência, condenações e mortes. Hoje ninguém mais corre o risco de ir para a fogueira por afirmar que a Terra gira em torno do Sol, fenômeno esse totalmente assimilado pela astronomia e ensinado aos estudantes nos seus primeiros anos de instrução formal. Em suma, fazer ciência é comportamento, e como tal é dinâmico, mutante em função das contingências históricas e atuais. 
Entre 1938 e 1990, Skinner (1904-1990) produziu dados experimentais e reflexões teórico/filosóficas que tiveram forte impacto no desenvolvimento da ciência denominada Análise do Comportamento. Em 1981, com a publicação do texto Selection by Consequences, ele formalizou a proposta que vinha sendo delineada nos seus escritos anteriores: a de que o comportamento é produto da seleção (pelas consequências) que se dá nos níveis filogenético, ontogenético e cultural. Considerando a importância e a polêmica gerada por essa proposta, a revista Behavioral and Brain Sciences publicou, em 1984, um número especial denominado Cannonical Papers of B. F. Skinner, contendo diversos textos representativos de diferentes momentos da trajetória desse autor. A dinâmica da publicação foi especialmente interessante pelo fato de que cada texto foi seguido de comentários críticos de diferentes cientistas (filósofos, antropólogos, sociólogos, biólogos, além de analistas do comportamento, entre outros) que, por sua vez, receberam a réplica de Skinner. Assim, além de se expor ao embate de ideias, próprio da atividade científica, Skinner teve oportunidade de elucidar questões relativas aos seus escritos que, na visão dele, algumas vezes eram compreendidos de forma equivocada.

Dá para imaginar que essa publicação fez brilhar os olhos de quem, nessa época, estava interessado na proposta skinneriana: era como assistir, quase ao vivo, um debate entre gigantes. Apesar de todas as críticas que a proposta angariou, sua relevância para os estudiosos do comportamento perdurou ao longo dos anos, de forma que hoje ela continua motivando reflexões e debates, essenciais para o avanço da ciência. Na comunidade brasileira de analistas do comportamento, esse interesse transparece nos dois conjuntos de textos que serão aqui analisados. O primeiro, publicado em 1988 pela revista Psicologia: Teoria e Pesquisa (volume 5, no. 2) o segundo apresentado em 2016 pela revista Interação em Psicologia (volume 20, no. 3). Em ambos, analistas do comportamento apresentaram o produto das suas reflexões sobre o modelo selecionista de Skinner, destacando aspectos que se relacionam com a sua atividade de pesquisa. Como fui uma das autoras presentes no conjunto de 1988, recebi dos editores da revista Interação em Psicologia a incumbência de comentar os atuais textos, buscando estabelecer uma ponte que unisse esses 28 anos. Para cumprir essa tarefa, vou apresentar os contextos nos quais foram produzidos os dois conjuntos, fazer um resumo dos artigos de 1988, apontando as questões mais debatidas ou as que geraram maior polêmica, e compará-las com as questões analisadas nos textos atuais. Talvez essa ponte nos ajude a vislumbrar a evolução que se processou na comunidade de analistas do comportamento no Brasil ao longo de quase três décadas e a identificar algumas das questões que permanecem em aberto para que sejam material de análise em futuras reflexões.

\section{O CONTEXTO DA PRODUÇÃO DOS DOIS CONJUNTOS}

Apenas após a vinda do Prof. Keller ao Brasil, no início dos anos 1960, os pesquisadores brasileiros entraram em contato com o behaviorismo skinneriano. Isso necessariamente implica em grandes diferenças de familiaridade com o pensamento de Skinner no momento da produção dos dois conjuntos de textos. No Brasil, em 1988, a análise do comportamento, com inspiração skinneriana, era uma abordagem que dava seus primeiros passos dentro da Psicologia, enquanto que em 2016 ela tem uma longa trajetória de influência em diversas atividades científicas, tais como: grande quantidade de pesquisas experimentais e teóricas; diversos programas de pós-graduação, em universidades de diferentes pontos do país; periódicos científicos especializados; sociedades científicas agregando grande número de associados que se auto definem analistas do comportamento.

Em paralelo a essas diferenças de contexto geral, deve-se levar em conta que uma proposta teórica depende não apenas do autor, que deixa registrados seus escritos, como da interpretação de quem os lê. Autor e leitores são, por sua vez, moldados pelas contingências decorrentes da sua história pessoal e profissional, muitas delas estabelecidas pela comunidade que os cerca. Ou seja, são fruto da sua época. Nesse sentido, os 28 anos decorridos entre as duas publicações podem ter algum efeito na leitura sobre os mesmos textos de Skinner.

\section{Os bastidores da publicação em 1988}

No início dos anos 1980, um trio de jovens doutores - Luís Cláudio M. Figueiredo, Maria Teresa A. Silva e Maria Helena L. Hunziker - se reunia semanalmente para discutir pesquisas experimentais desenvolvidas em conjunto, porém em laboratórios separados: Figueiredo e Silva no Departamento de Psicologia Experimental (PSE) da USP e Hunziker no Departamento de Farmacologia da UNICAMP. Ao longo dessas reuniões, percebeu-se que o trabalho experimental requeria o aprofundamento de questões de âmbito filosófico. A 
publicação relativa aos "textos canônicos" de Skinner acabava de ser lançada, de forma que ela foi a escolha para se fazer um estudo sistemático sobre o pensamento skinneriano. Rapidamente, essa temática atraiu outras pessoas que se juntaram ao trio: Maria Lúcia D. Ferrara (Tutu) e Lígia Maria C. M. Machado, ambas do PSE da USP, Tereza Maria A. P. Sério (Téia) e Maria Amália P. A. Andery, da PUC-São Paulo.

Decorridos muitos meses de estudos e discussões, surgiu a ideia de apresentar o produto desses encontros em uma reunião científica como forma de ampliar o debate que era feito entre os sete participantes. Assim, foi planejada uma Mesa Redonda na qual seria debatido o modelo de seleção pelas consequências, ficando a discussão sobre cada nível de seleção a cargo de dois participantes do grupo. Figueiredo ficou responsável pela análise global e a Profa. Maria Amélia Matos foi convidada para coordenar a realização dessa atividade, que ocorreu na XVI Reunião Anual de Psicologia de Ribeirão Preto, promovida pela SPRP, em 1987. O resultado foi um debate vigoroso, que logo depois foi publicado, compondo o conjunto de 1988 a ser analisado aqui.

Em relação aos autores, com exceção de Sério e Andery, todos os demais desenvolviam pesquisa experimental com animais, tendo Matos sido a orientadora de Mestrado e/ou Doutorado da maioria deles. Além disso, todos trabalhavam em instituições paulistas (na capital, exceção de Hunziker, na UNICAMP, ou seja, a meros $100 \mathrm{~km}$ de São Paulo), caracterizando um grupo geográfica e academicamente homogêneo.

Quanto ao estado da arte, pode-se dizer que os três níveis de seleção não eram pesquisados de maneira equitativa. A produção experimental era toda centrada no estudo do comportamento em nível ontogenético, de forma que a proposta da seleção nos demais níveis existia com base em evidências indiretas (oriundas da biologia e ciências afins, para o nível filogenético), ou era meramente especulativa (como a proposta de seleção pelas consequências na cultura). Dentre os opositores de Skinner, a proposta de seleção no nível filogenético recebia duas críticas opostas: uma afirmava que o behaviorismo era "pouco biológico", não levando em conta os determinantes pré-ontogenia na explicação do comportamento; outra, argumentava que o behaviorismo era excessivamente biológico, dando ao organismo o status de causador do comportamento, o que comprometia a proposta da psicologia como ciência autônoma. Quanto à análise selecionista da cultura, ela tinha pequena pro- jeção, não tendo ainda gerado pesquisas e reflexões sistemáticas dentre os analistas do comportamento.

\section{Os bastidores da publicação em 2016}

A publicação de 2016 segue algumas das características do conjunto anterior: são textos dedicados à análise crítica do modelo de seleção pelas consequências, com um comentário final que busca interliga-los.

Dentre as diferenças, a primeira relaciona-se à composição do grupo de autores. Em 1988 ele era homogêneo, não apenas geográfica como academicamente. Pode-se dizer que aqueles autores compunham a segunda geração de analistas do comportamento no Brasil, todos com forte influência de uma das representantes da primeira geração, Maria Amélia Matos que, por sua vez, teve sua formação diretamente a cargo de behavioristas norte-americanos aliados a Skinner (Keller e Schoenfeld). Os autores condidatos de 2016 compõem um grupo heterogêneo, com formação bastante diversificada (diferentes orientadores, em diferentes programas de pós-graduação) e que atuam em universidades de diversas regiões do país: Pará (Marcus Bentes de Carvalho Neto ${ }^{1}$ e François Tonneau), Espírito Santo (Diego Zilio), Paraná (Carlos Lopes e Carolina Laurenti), São Paulo, na capital (Nilza Micheletto) e em Bauru (Kester Carrara). Em comum eles têm basicamente o fato de pertencerem a uma mesma comunidade científica, a dos analistas do comportamento no Brasil. Pode-se sugerir que essa heterogeneidade atual seja um reflexo desses 28 anos, durante os quais uma ciência que era centrada basicamente em São Paulo se irradiou pelo país, tendo evoluído com independência em relação a lideranças acadêmicas.

Ainda sobre a diferença entre os autores, está o fato de que em 1988 a maioria se dedicava ao trabalho experimental de laboratório, com animais. No grupo de 2016, embora alguns autores tenham também produção experimental, não é ela que os caracteriza: todos têm a ênfase da sua produção acadêmica no âmbito teórico/filosófico/conceitual.

As origens de ambas as publicações também diferem. Os textos de 1988 decorreram de uma atividade em congresso científico, feita por um grupo de pesquisadores que de forma pioneira se dispuseram a analisar o modelo skinneriano; os de 2016 foram fruto de um convite feito a pesquisadores que se projetam cientificamente no cenário nacional pela sua produção teórica envolvendo reflexão sobre o behaviorismo. Portanto, se 
em 1988 a publicação trazia pioneirismo, em 2016 ela traz maturidade.

Em relação ao estado da arte, aparentemente foi o estudo da seleção no terceiro nível o que mais evoluiu: em 2016 a produção brasileira é referência nos estudos nessa área, juntamente com os trabalhos de Glenn. Em relação ao primeiro nível, em 2016 verifica-se que foi fortemente reduzido o preconceito em relação às variáveis biológicas incluídas na contingência comportamental. Um evidencia disso é o espaço crescente que a área vem dando à análise biocomportamental (Donahoe \& Palmer, 1992), que propõe diálogos entre a Análise do Comportamento e as Neurociências sem perda de autonomia de qualquer das ciências envolvidas. Contudo, longe das críticas simplistas como as citadas nos anos 1980, ainda existe nos tempos atuais demanda para que novas análises sejam desenvolvidas sobre o papel do organismo no estudo do comportamento (ver, por exemplo, análise de Zilio, 2013).

Essas diferenças de contextos na produção de ambos os conjuntos possivelmente influenciaram as diferenças que veremos entre eles. Em relação às análises no primeiro nível, eles não mais precisaram "explicar" a proposta skinneriana englobando o organismo no estudo do comportamento, podendo se aprofundar nas análises críticas relativas à seleção na filogenia. Na análise do terceiro nível, em 2016 os autores puderam lidar com pesquisas e reflexões teóricas bem desenvolvidas em relação à seleção cultural.

\section{CONSIDERAÇÕES SOBRE O MODELO DE SELEÇÃO PELAS CONSEQUÊNCIAS EM 1988}

A análise da seleção na filogenia foi feita por Silva e Hunziker (1988) que desenvolviam pesquisas experimentais incorporando variáveis farmacológicas nas contingências em estudo. Dado o preconceito vigente na época, descrito anteriormente, esse texto ficou concentrado na desconstrução desses entendimentos equivocados, buscando trazer à tona a real proposta de Skinner quanto ao primeiro nível de seleção. Assim, diferentemente dos demais, esse texto teve ênfase mais esclarecedora do que crítica.

Silva e Hunziker (1988) utilizaram trechos da obra de Skinner para rebater asserções equivocadas do tipo "o behaviorismo não considera a importância da herança genética no comportamento", "essa filosofia considera o organismo como uma tabula rasa" ou que " não há diferenças entre as espécies" ou "todas as respostas são condicionáveis a todos os estímulos", entre outras.
Ao longo do texto foi dado destaque à proposta de Skinner de analogia do seu modelo com o de seleção natural darwiniano, no sentido de que o comportamento evolui (muda) em função da "preservação das variações favoráveis e à rejeição das variações desfavoráveis" (p. 146). Foram contextualizadas algumas afirmações de Skinner que, vistas isoladamente, soavam ameaçadoras à independência da psicologia como ciência, tais como: "todo comportamento é herdado" ou " sendo o comportamento a fisiologia de uma anatomia, a hereditariedade do comportamento é a hereditariedade de certas características orgânicas" (p. 145). Destacou-se que, para Skinner, o herdado geneticamente seriam algumas características do organismo, dentre elas algumas que poderiam influenciar "a sensibilidade diferencial a determinados reforçadores, contingências de reforço, estímulos que podem se tornar discriminativos, etc." (p. 147). Como único ponto crítico, Silva e Hunziker questionaram a abrangência do modelo skinneriano, apontando que o controle pelo antecedente, próprio das relações respondentes, ficou de fora do modelo de controle pelas consequências: "embora ele [o condicionamento respondente] não escape à determinação filogenética, na visão skinneriana a aprendizagem que mostra um marcante paralelo com a seleção natural é a operante" (p. 147).

Em relação à seleção no nível ontogenético, Machado e Ferrara (1988) lançaram mão de dados experimentais para sugerir que a proposta do modelo skinneriano não seria suficiente para compreender o comportamento como um todo. Segundo elas, ao menos três conjuntos de dados experimentais não podiam ser explicados pelo modelo de seleção pelas consequências: 1) a seleção pela contiguidade temporal (amparada pelo estudo experimental de Skinner, sobre comportamento supersticioso); 2) outras funções do reforço, além da puramente seletiva, tais como as indutoras, inibidoras, discriminativas ou eliciadoras; 3) processos não operantes de determinação do comportamento, tais como o condicionamento respondente, aprendizagem por modelação, períodos sensíveis para determinada aprendizagens, e emergência de classes de estímulos equivalentes. Para Machado e Ferrara, o problema maior da proposta de Skinner é a pretensão desse autor de sugerir um único mecanismo, ainda não completamente descrito nem explicado no nível ontogenético, como modelo que pode oferecer um referencial para estudo da seleção natural e da seleção da cultura. Além disso, consideraram questionável se respostas em um nível são igualmente válidas e funcionais em outros. Em úl- 
tima instância, não afirmaram que o modelo proposto por Skinner estivesse equivocado, mas sim que, naquele momento, ele significava "um passo maior do que podem aguentar as pernas do nosso conhecimento agora” (p. 143).

A análise da seleção no terceiro nível foi realizada por Andery e Sério (1988), sendo suas considerações bastante críticas em relação à abordagem skinneriana, especialmente quanto à visão de história demonstrada por esse autor. Elas analisaram citações de Skinner que indicavam oscilações conceituais e algumas lacunas no modelo proposto. Por exemplo, as definições de Skinner sobre cultura variam ao longo da sua obra; a abordagem skinneriana ora enfatiza a cultura como um fator de controle sobre o comportamento dos indivíduos, ora a própria cultura como o "sujeito" dessa seleção. Ao analisarem o conflito indivíduo versus grupo, concluíram que Skinner afirmava a primazia do grupo sobre o indivíduo, "embora frequentemente aponte o homem particular como medida e como objeto da cultura, chegando a afirmar que o homem é a medida de todas as coisas" (p. 152). Essa opção pelo grupo, somada à perspectiva evolucionista da cultura (especialmente quanto à compreensão da variação como processo aleatório), foram aspectos que levaram as autoras a criticar a noção skinneriana de história: “... ao abordá-la como um paralelo da evolução, a história acaba sendo reduzida à seleção...” (p. 153). Por fim, foi apontada a necessidade de se compreender melhor a concepção de ciência de Skinner, de forma a explicitar se ele tem ou não "o homem como sujeito da história e como construtor da cultura e de si mesmo" (p. 154).

Figueiredo (1988) e Matos (1988) revelaram conclusões opostas frente às análises apresentadas. Figueiredo considerou que a seleção pela consequência, como modelo, é pobre enquanto descrição-explicação do comportamento, sendo mais aceitável atribuir-lhe "uma função heurística, orientando as práticas de investigação, a procura de regularidades e a organização dos dados. E isso nas três áreas em exame" (p. 155). Também afirmou que, por serem simplificações, os modelos nunca abarcam totalmente os fenômenos em estudo e que, em relação ao modelo em análise, seu alcance ficou especialmente reduzido no nível da evolução da cultura. Para ele, também foi motivo de crítica a visão skinneriana sobre a variação do comportamento: sugeriu que o melhor que o modelo de Skinner teria a oferecer seria "o incentivo para estudo dos mecanismos e processos de produção de variações e indução de novidades. Acreditar numa variação puramente aleatória é discutível no campo da genética, mas parece ser indiscutivelmente um absurdo nos processos de desenvolvimento individual e históricos" (p. 155). Ele finalizou criticando o fato de que, após haver deixado o laboratório, Skinner passou a se dedicar a um discurso prescritivo de soluções para os problemas humanos, sem base experimental para isso. Textualmente, ele afirmou "Assusta-me nesta, como em quase todas as elucubrações de Skinner desde que abandonou o laboratório, a facilidade com que ele dá a impressão de ter resolvido intrincadas questões mediante um mero jogo de ideias e a arrogante generosidade com que ele oferece suas soluções à comunidade científica" (p. 156).

Por sua vez, Matos (1988) assumiu uma posição de defensora incondicional da proposta skinneriana. Ela destacou o valor heurístico do modelo de seleção pelas consequências que gerou uma grande quantidade de pesquisas experimentais e o surgimento de uma nova área na ciência. Também discordou que a proposta de Skinner assuma uma variação aleatória: em paralelo à plasticidade do comportamento apontada por Skinner em diversos textos, ela citou os trabalhos de Neuringer que demonstram a variação do comportamento controlada pelas consequências (variabilidade operante). Argumentou também que o modelo skinneriano não exclui, mas suplementa, o modelo pavloviano, e que o comportamento verbal, sobre o qual Skinner se debruçou teoricamente, impacta sobremaneira o terceiro nível de evolução. Ela finalizou sugerindo que o modelo de seleção pelas consequências, por ser recente na história das ciências, precisava de mais tempo e pesquisa para ser discutido. Segundo ela, vários problemas deverão ainda ser resolvidos na psicologia "antes que os ânimos possam serenar o suficiente para sequer aceitarmos discutir o modelo selecionista" (p. 158).

Em resumo, pode-se dizer que esse conjunto de textos expressava, no geral, reconhecimento da importância da proposta de Skinner para o estudo do comportamento, porém com críticas que exigiam revisões ou reformulações da mesma. Destacaram-se como críticas mais contundentes (embora sem unanimidade): 1) o modelo não abarcar todos os processos de determinação do comportamento já conhecidos experimentalmente na ontogenia; 2) a compreensão do processo de variação como sendo aleatório; 3) a teorização, sem base experimental, em relação à seleção nos níveis filogenético e cultural; 4) a suposição de que de processos conhecidos no nível ontogenético seriam igualmente válidos em outros níveis; 5) o conflito indivíduo vs grupo; 6) a simplificação trazida pelo modelo 
que acarretou fragilidade especialmente na sua aplicação ao estudo da evolução da cultura.

\section{CONSIDERAÇÕES SOBRE O MODELO DE SELEÇÃO PELAS CONSEQUENCIAS EM 2016}

A leitura dos textos apresentados nesse conjunto de 2016 mostra que esses 28 anos fizeram diferença nas considerações feitas sobre o modelo skinneriano. Além do aprofundamento de diversas questões trazidas pelo conjunto de 1988 (exceção apenas da seleção no nível ontogenético), os textos atuais ampliaram os aspectos abordados sobre a proposta.

A analogia feita por Skinner com o modelo de seleção natural de Darwin recebeu duas análises. A primeira foi a crítica sobre a (in)adequação do uso da analogia em ciência, feita por Tonneau (2016), reiterando publicações anteriores suas. A tônica dessa análise é que a analogia raramente contribui para uma melhor compreensão do fenômeno em estudo, sendo muitas vezes enganosas ou triviais. Segundo Tonneau, a analogia da seleção por consequências com a seleção natural é inútil por ser trivial: a proposta sobre reforçamento operante foi feita por Skinner em 1938, muito antes do estabelecimento da analogia com a seleção natural (formalizada em 1981), que não revelou basicamente nada que já não fosse conhecido. Consequentemente, essa analogia não teve impacto nos avanços empíricos e teóricos dessa área científica

Com outro olhar, Lopes e Laurenti (2016) não questionaram o uso de analogias, em si, mas sugeriram que outra analogia, que não a darwiniana, é, atualmente, mais adequada ao modelo de seleção pelas consequências: a teoria evolutiva neolamarckista. Segundo eles, um aspecto que aproxima a proposta de Skinner do modelo darwiniano (ou, mais recentemente, do neodarwiniano) é a suposição de que as variações são aleatórias, ou seja, a experiência ontogenética do organismo não interfere no curso evolutivo da espécie. Contudo, dados de outras ciências (tais como a epigenética) vêm contradizendo essa aleatoriedade da variação, o que dá sustentação experimental à proposta neolamarckista de que a experiência ambiental do organismo interfere no processo evolutivo. Em outras palavras, a aprendizagem pode influir na evolução. Lopes e Laurenti utilizaram diversas citações de Skinner que mostram conflitos e incoerências conceituais sobre o processo de variação, selecionando diversas que podem ser colocadas lado a lado com o atual pensamento neolamarckista. Para eles, essa reinterpretação do pensamento skinneriano pode aumentar a proximidade da análise do comportamento em relação à biologia evolutiva, propiciando maiores oportunidades de colaboração entre ambas as ciências.

No nível de seleção cultural, Carrara (2016) analisou duas questões que são estruturais para o refinamento teórico/conceitual/experimental dos estudos nessa área: a definição da unidade de análise e a necessidade (ou não) de serem propostos novos processos comportamentais além dos existentes para o estudo do comportamento do indivíduo. Sobre a unidade de análise, Carrara confrontou duas possibilidades: a seleção se dá 1) sobre o comportamento do indivíduo no grupo ou 2) sobre o comportamento do grupo. Carrara desenvolve argumentos que o direcionam para a retomada da proposta original skinneriana, manifesta em 1953 no Science and Human Behavior. Apesar de apontar que Skinner oscilava entre priorizar o grupo ou o indivíduo como o centro da sua análise, Carrara concluiu que, no cerne da proposta skinneriana, é o indivíduo que se comporta. Portanto, no estudo da cultura, a unidade de análise é o comportamento do indivíduo (no grupo). A segunda questão deriva da anterior: se é o comportamento do indivíduo que é selecionado (na cultura), e se a tríplice contingência é o instrumento necessário e suficiente para analisar o comportamento do indivíduo, então ela também é o instrumento necessário e suficiente para os estudos do terceiro nível de seleção. Consequentemente, Carrara se posiciona criticamente em relação à literatura atualmente voltada para o estudo da seleção no terceiro nível - que segue, na sua maioria, a proposta de Glenn e colaboradores - afirmando não ser necessário que se lance mão de novos conceitos e processos, tais como metacontingência, produto agregado, e outros, para o estudo da seleção cultural.

Zilio (2016) caminha na mesma direção de Carrara (2016), especialmente em relação a três aspectos: 1) ser desnecessária a proposição de novos conceitos e processos para explicar a cultura; 2) a tríplice contingência ser o instrumental necessário e suficiente para que sejam analisados comportamentos individuais ou sociais.; 3) o comportamento do indivíduo, e não o do grupo, é que é selecionado. Além disso, Zilio analisa problemas surgidos pelo uso de metáforas/analogias no estudo das culturas. Nesse contexto, ele sugere que a proposta skinneriana de 1953 não envolve, de fato, um terceiro "tipo" de seleção, mas apenas indica que contingências culturais são tipos especiais de contingências ontogenéticas que envolvem comportamentos de mais de um sujeito. Ele discorda da análise de Glenn e colaboradores sobre três pontos: 1) por considerar a seleção cul- 
tural como um terceiro "tipo" de seleção; 2) por adotar novos processos e conceitos, além dos desenvolvidos no nível de seleção ontogenético; 3) por ampliar o uso de metáforas selecionistas sem sustentação experimental. Zilio sugere uma análise da cultura sem o uso de metáforas e sem supor esse terceiro nível, concordando com Carrara (2016) de que a proposta original de Skinner, em 1953, é a mais parcimoniosa.

Carvalho Neto, Guimarães, Sarmiento e Leão (2016) retomaram uma crítica que ocorreu em diversos textos de 1988: o fato de o selecionismo não explicar o comportamento/condicionamento respondente. Eles analisaram que esse fato sugere que o selecionismo não é um princípio geral do comportamento, bem como que a crítica skinneriana à explicação mecanicista do comportamento deve ser relativizada, pois ela ainda é a melhor descrição do comportamento respondente. Pode-se dizer que Carvalho Neto et al. reafirmaram a crítica de Machado e Ferrara (1988), no que diz respeito a "dar um passo maior que a perna": se o acúmulo de dados experimentais ainda não permitiu que fossem resolvidos os problemas do modelo selecionista no nível ontogenético, como sustentar sua extrapolação para os demais níveis de seleção, onde tais derivações são puramente teóricas?

Dois tópicos surgidos em 2016 não estavam presentes em 1988. O primeiro deles diz respeito à análise conceitual dos termos utilizados. Leão e Carvalho Neto (2016) questionaram o uso que se faz do termo selecionismo (ou seleção por consequências). Segundo eles, mesmo sendo característico da análise skinneriana, esse termo não conta com uma definição consensual: em alguns casos ele é utilizado como um modo explicativo, em outros apenas indica a opção por um posicionamento epistemológico. Com base em três textos de Skinner, os autores propuseram três critérios definidores do sistema explicativo de seleção pelas consequências: o fato desse sistema ser considerado (1) um modo causal do comportamento, fundamentado em uma (2) relação de interdependência probabilística entre eventos, cuja evolução se dá como (3) função conjunta dos processos de variação e seleção que se passam no ambiente evolutivo da espécie, no tempo de vida do indivíduo e na sua cultura.

A segunda análise surgida em 2016, sem paralelo nos textos de 1988, foi a que mostra as mudanças ocorridas na proposta skinneriana ao longo dos anos, com reflexos no modelo de ciência desenvolvido por Skinner. Em adição às considerações sobre o pensamento skinneriano relativo ao conhecimento e ao comportamento do cientista, Micheletto (2016) transcreve citações retiradas do início e do final da obra skinneriana mostrando que aos dois pilares iniciais- observação e experimentação - foram acrescentadas a especulação e a interpretação. Segundo Micheletto, essas mudanças se processaram quando foi destacado na obra de Skinner o caráter histórico do comportamento, de forma que apenas a observação do evento no presente não permitia sua explicação. Também influenciaram nessa mudança a expansão da análise que inicialmente era restrita ao laboratório para fora dele onde a previsão exata não é possível. Segundo Micheletto, essas novas propostas não implicaram, contudo, em abandono da defesa da experimentação, mas sim em uma noção de experimentação ampliada, extrapolando os limites do laboratório até chegar às dimensões culturais. Em outras palavras, Skinner passou a assumir explicitamente a interpretação e a especulação desde que feitas a partir dos resultados do laboratório, de forma que pode ser considerado que a experimentação continuou sendo sua estratégia de escolha, quando possível.

Comparativamente aos textos de 1988, existe, no geral, grande concordância de que a obra de Skinner, embora seminal para o desenvolvimento científico da análise do comportamento, é repleta de imprecisões, confusões conceituais, incoerências. Essas constatações críticas foram o alvo da maior parte dos artigos aqui analisados (embora nem sempre com unanimidade), sendo a tônica da maioria dos textos que tais problemas, embora necessitem de revisões, não são motivo para o descarte do modelo: assume-se que a proposta skinneriana tem sido, e continua sendo, bastante útil ao desenvolvimento científico da análise do comportamento.

Os textos sugerem que a falta de clareza de Skinner em relação a diversos conceitos tem favorecido compreensões díspares sobre seus escritos. Por exemplo, em relação ao conceito de cultura, Carrara (2016) destacou a diversidade de definições oferecidas por Skinner, fortalecendo a análise feita por Andery e Sério (1988). Mesmo sem o contraponto nos textos anteriores, Micheletto (2016) reforça essa noção de que a obra de Skinner apresenta variações conceituais ao longo dos anos, enquanto Leão e Carvalho Neto (2016) questionam o significado do termo selecionismo nessa obra. $\mathrm{O}$ que se pode depreender da leitura dos textos de ambos os conjuntos é que cada autor acaba selecionando as definições e conceitos que considera mais representativos da obra ou da sua leitura da obra skinneriana 
como um todo.

Os conflitos sobre a análise skinneriana em relação ao processo de variação - essencial em um modelo que tem suas bases no duo variação e seleção -, tiveram diferentes abordagens nos dois conjuntos de textos. Por exemplo, no debate final do conjunto anterior, ficou patente as diferentes compreensões sobre esse tema: enquanto Figueiredo (1988) criticou como absurda a noção skinneriana de que a variação se dá por processos aleatórios, Matos (1988) afirmou que a aleatoriedade não era inevitavelmente a concepção derivada do modelo de seleção pelas consequências. Analisando esse tema na atualidade, Lopes e Laurenti (2016) encontraram nos trabalhos da biologia evolutiva dados aparentemente compatíveis com a análise skinneriana.

De uma maneira geral, a não aceitação da analogia do modelo selecionista skinneriano com o darwiniano é uma marca desse conjunto de 2016. Quer pela discordância em relação ao uso de analogias (Tonneau, 2016), quer pela sugestão de que o neolamarckismo é, hoje, a analogia mais apropriada ao selecionismo de Skinner (Lopes \& Laurenti, 2016), tais considerações contrastam com a aceitação sobre a analogia com a seleção natural darwiniana, apresentada por Silva e Hunziker (1988) e também adotada por outros autores do conjunto de 1988 .

Outras questões que estiveram presentes em ambos os conjuntos é a não explicação do condicionamento respondente por processos selecionistas (Carvalho Neto et al, em 2016, e diversos autores em 1988) e o conflito indivíduo vs grupo. Em relação a esse último ponto, a conclusão de Carrara (2016) de que a ênfase da análise skinneriana recai sobre o indivíduo contrasta com a conclusão de Andery e Sério (1988), que apontaram a opção de Skinner pelo grupo. Pode-se argumentar que essa questão tem diferentes nuances. Ao se questionar a visão de história de Skinner, surge a questão ética, na qual o valor supremo é o da sobrevivência da cultura, o que permite que se diga que ele opta pelo grupo. Contudo, ao se discutir a unidade de análise do seu modelo, em diversos momentos da sua obra Skinner define que é o indivíduo que se comporta; logo, o indivíduo é o centro da sua análise, mesmo quando se comportando em grupo.

Além das diferenças que podem ser identificadas após os 28 anos aqui considerados, os textos de 2016 trouxeram também a noção de que uma das áreas que mais cresceu no período, o do estudo da seleção na cultura, não está isenta de conflitos. Tanto Carrara (2016) quanto Zilio (2016) mostraram discordâncias em relação a uma das linhas de investigação de maior destaque atual nessa área, a de Glenn e colaboradores, que sugere novos conceitos e processos para o estudo da cultura (metacontingência, produto agregado, entre outros). Carrara e Zilio propuseram que a cultura pode ser analisada sem a necessidade desses novos conceitos ou processos, sendo suficientes aqueles que têm se mostrado útil no estudo do comportamento do indivíduo. Levando ao extremo, Zilio sugeriu não existir um terceiro nível de seleção. Segundo ele, o destaque skinneriano para a seleção na cultura não implica em um tipo diferente de seleção, mas sim que a seleção da cultura se dá na ontogenia, com a única diferença que trata de comportamentos de mais de um indivíduo concomitantemente.

Resumindo, os textos de 1988 e 2016 concordam que a proposta do modelo de seleção pelas consequências foi um marco na análise do comportamento, sendo geralmente identificado como definidor dessa ciência. Com algumas exceções, também concordam que esse modelo, conforme proposto por Skinner, envolve ao menos os aspectos que seguem: 1) a analogia com o modelo de seleção natural, de inspiração darwiniana; 2) a existência de três níveis de seleção (filogenético, ontogenético e cultural) que atuam em conjunto obedecendo a um mesmo princípio geral; 3) a consequenciação como princípio geral do comportamento, do mais simples ao mais complexo, do individual ao grupal; 4) o selecionismo se opondo a explicações do comportamento de cunho mecanicista, mentalista, essencialista, criacionista, entre outras; 5) as bases experimentais do modelo estão no nível ontogenético, sendo os demais níveis de variação propostos como extensões especulativas a partir deste. A despeito das críticas, os textos aqui analisados sugerem que, mais do que afastar novos pesquisadores, os problemas apontados no modelo de seleção pelas consequências têm sido motivo de reflexões, revisões, autocríticas e reformulações que (espera-se) podem levar a um refinamento teórico/filosófico que represente um avanço no estudo do comportamento.

Buscando um olhar à frente, podemos nos perguntar que outras considerações poderiam ser acrescentadas a esses dois conjuntos para dar continuidade a esse refinamento. Nota-se que o conjunto de 2016 não analisou estudos experimentais recentes que pudessem fundamentar (ou refutar) a seleção no nível ontogenético. Como é nesse nível que a análise do comportamento tem suas bases experimentais solidamente estabeleci- 
das, é de se esperar que ele possa trazer contribuições expressivas para as análises desenvolvidas sobre a obra de Skinner. A análise da lógica interna da posposta skinneriana, inserindo-a à filosofia geral da ciência, traz contribuições de peso para a área. Mas, que avanços podem se dar se a elas forem somadas análises das implicações de dados experimentais recentes para o modelo em questão? Por exemplo, será que os dados atuais sobre equivalência de estímulos confirmam a sugestão de Machado e Ferrara (1988) de que esse fenômeno comportamental se contrapõe à proposta de seleção pelas consequências? Outra linha de pesquisa que pode ser de grande utilidade na análise do pensamento skinneriano é a que abarca os estudos experimentais de Neuringer e colaboradores, que mostram que a variabilidade do comportamento pode ser selecionada pelas suas consequências. As implicações diretas que esses estudos têm para a discussão sobre os mecanismos comportamentais da variação é inequívoca e instigante por subverter a compreensão usual dos mecanismos de seleção e variação: vistos normalmente como opostos (embora complementares), eles adquirem maior dinamismo ao se considerar a seleção da variação. Uma terceira linha de estudos experimentais que pode ajudar na discussão sobre a seleção na ontogenia é a que trata dos efeitos comportamentais de estímulos não contingentes, tais como se vê no estudo do desamparo aprendido: se apesar de não serem consequentes ao comportamento esses estímulos modificam sua probabilidade de ocorrência, como analisar essa mudança comportamental como fruto de seleção pelas consequências? Será que esses estudos reavivam a velha discussão sobre a seleção pela contiguidade, conforme citado por Machado e Ferrara (1988)? Além dos estudos operantes, pesquisas recentes sobre condicionamento respondente deveriam ser também incorporadas fornecendo a base experimental para a análise sobre a adequação ou limites da proposta do modelo selecionista de Skinner como explicativo de todo o fenômeno comportamental.

Enfim, há muito que se buscar no laboratório para nortear as discussões teórico/filosóficas sobre o modelo de seleção pelas consequências. Se é sobre as evidências no nível ontogenético que são feitas as especulações estendidas aos níveis filogenéticos e cultural, então a análise da seleção na ontogenia deve estar sempre na base das demais considerações. Por mais inebriante que seja a análise teórica - e é, pois, ela permite voos audaciosos -, na experimentação está a terra firme, aquela que ajuda que esses voos não percam seu rumo.

\section{REFERÊNCIAS}

Andery, M. A. P. A. \& e Sério, T. M. A. P. (1988). O controle pela consequência no desenvolvimento da cultura. Psicologia: Teoria e Pesquisa, 5, (2), 149-155.

Carrara, K. (2016). Consequências nas práticas culturais: efeitos sobre indivíduos ou grupos? Interação em Psicologia, 20, (3), 246-256.

Carvalho Neto, M. B., Guimarães,T. M. M., Sarmiento, A. R. e Leão, M. F. F. C. (2016). O (não) lugar do reflexo no modo causal de seleção pelas consequências de Skinner. Interação em Psicologia, 20, (3), 305-309

Donahoe, J. W. e Palmer, D. C. (1994). Learning and Complex Behavior. Boston: Allyn and Bacon.

Figueiredo, L. C. M. (1988). Controle pelas consequências: Questões em aberto. Psicologia: Teoria e Pesquisa, 5, (2), 155-156.

Leao, M. F. F. G. \& Carvalho Neto, M. B. (2016). Afinal, o que é seleção por consequências? Interação em Psicologia, 20, (3), 286-294.

Lopes, C. E. \& Laurenti, C. (2016). Elementos neolamarckistas do selecionismo skinneriano. Interação em Psicologia, 20, (3), 257-267.

Machado, L. M. C. M. \& Ferrara, M. L. D. (1988). O controle pela consequência na ontogênese do comportamento. Psicologia: Teoria e Pesquisa, 5, (2), 139-144.

Matos, M. A. (1988). O modelo de consequenciação de B. F. Skinner: as propriedades da evolução. Psicologia: Teoria e Pesquisa, 5, (2), 156-158.

Micheletto, N. (2016). Seleção por consequências: desdobramentos para a noção de ciência de B. F. Skinner. Interação em Psicologia, 20, (3), 295-304.

Silva, M. T. A. \& Hunziker, M. H. L. (1988). O controle pela consequência na filogênese do comortamento. Psicologia: Teoria e Pesquisa, 5, (2), 145-149.

Skinner, B. F. (1981). Selection by consequences. Science, 213 (4507), 501-504.

Tonneau, F. (2016). Reforçamento operante e seleção natural: A analogia inútil. Interação em Psicologia, 20, (3), 279285.

Zilio, D. (2013). Análise do comportamento e neurociências: em busca de uma possível síntese (Tese de Doutorado). Universidade de São Paulo, São Paulo.

Zilio, D. (2016). Selecionismo, metáforas e práticas culturais: Haveria um terceiro tipo de seleção no nível cultural? Interação em Psicologia, 20, (3), 268-278.

Artigo convidado Recebido em: 31/12/2016

\section{Nota:}

1 Que incluiu alguns orientandos como seus co-autores. 